\title{
Evolution of Photonics Education at the Australian National University
}

\section{John Love}

John Love, "Evolution of Photonics Education at the Australian National University," Proc. SPIE 9666, 11th Education and Training in Optics and Photonics Conference, 966615 (5 June 2009); doi: 10.1117/12.2208033

Event: Eleventh International Topical Meeting on Education and Training in Optics and Photonics, 2009, St. Asaph, United Kingdom 


\title{
Evolution of Photonics Education at the Australian National University
}

\author{
John Love \\ Department of Quantum Science, College of Physical Sciences, \\ The Australian National University, Canberra, ACT 0200, Australia \\ (E-mail: John.Love@anu.edu.au)
}

\begin{abstract}
This paper tracks the evolution of photonics education and training at the Australian National University (ANU) from its tentative beginnings in 1971 in the doctoral and masters postgraduate research arena and in 1989 in the undergraduate teaching arena through to its substantive role in 2009 and onwards. In addition it addresses various offshoots to national and international outreach activities and support for emerging photonics qualifications at other institutions, as well as photonics conference evolution.
\end{abstract}

Keywords: Photonics, optical fibres, lecture courses, photonics degrees, outreach, science schools, photonics conferences

\section{Introduction}

Optics has long been a strong tradition of research and development in Australia, partly enhanced by the country's strategic location in terms of astronomical access to the southern night sky and partly due to its high international standing and reputation for research and expertise in areas such as holography and the production of precision optical devices, and more recently in optical fibres, devices and applications. With regard to the latter, names such as Beattie Steel and Hariharan spring to mind. It is only since the mid-1960's when photonics began to make its presence felt in Australia that a whole new research and production industry evolved that has fluctuated with normal market pressures, including the great dot-com boom in the 1990's and the subsequent bust in 2000. Now towards the end of the first decade of the $21^{\text {st }}$ century, progress in photonics has reverted to the more normal increase that continues to follow Moore's Law of doubling in demand for bandwidth about every 9 months.

For a country of its size and with a population of only 20 million, Australia has punched well above its weight in terms of photonics research and development, photonics education and training, and photonics commercialisation and exporting. Commensurate with the exponential growth in photonics activity, a parallel growth in photonics education and training occurred in the tertiary education sectors, including a significant number of major universities, TAFE's (Technical and Further Education) in the six states and the equivalent in the Australian Capital Territory (Canberra), as well as the incorporation of basic fibre light-guiding into secondary school physics curricula. Indeed, several named photonics degrees were launched by various institutions in the heady 1990's but have now been rationalised. A small number of commercial photonics training companies also appeared and there was an impressive level of outreach activity stemming from universities and photonics-based independent research groups that also spread to some south-east 
Asian countries through Australian Government financial support. This has now subsided to more realistic proportions.

Another factor in the photonics education and training equation is the Australian Conference on Optical Fibre Technology (ACOFT) that emerged in 1984 out of an existing series of optical fibre workshops started in 1977 by Professor Toni Karbowiak. This annual conference has become the keystone for the reporting of photonics research progress in Australia and New Zealand and has attracted an impressive array of co-located leading international photonics-based conferences to the our shores, as well as incorporating workshops and photonics schools. This conference is now in its $34^{\text {th }}$ year and is well set to continue far into the future.

\section{Research Training}

The first photonics research training in Australia started in the Department of Electrical Engineering at the University of New South Wales (UNSW) in 1966 with the arrival of Professor Toni Karbowiak from STL in the UK. Indeed the very first PhD student was the late Professor Pak Chu who went on the take over the leadership of the Optical Communications Group when Professor Karbowiak retired and later when Professor Chu retired from UNSW he moved to the City University of Hong Kong to head the Opto-Electronics Group. At ANU, the Department of Applied Mathematics in the Research School of Physics of the Institute of Advanced Studies hosted the first photonics research group in the early 1970's under the leadership of Professor Allan Snyder. This theory group rapidly expanded and I had the pleasure of becoming a member in 1973. A large number of Ph.D's was produced together with a small handful of masters degrees by research, the latter normally occurring because of a change in circumstance inhibiting progress towards a doctorate.

A culmination of the voluminous research output from this group appeared in 1984 as the book entitled "Optical Waveguide Theory" written by Professor Snyder and myself. It has since appeared in Russian and Chinese editions, is still in print after 25 years and is generally regarded as the classic on the subject. A second book appeared in 1996 entitled "Silica-based Buried Channel Waveguides and Devices" written by Professor François Ladouceur and myself, and is based on a combination of theory and experimental development using plasma deposition and etching processes, the latter undertaken in collaboration with Professor Rod Boswell at ANU.

\section{Photonics Lecture Courses}

The first short lecture course in guided photonics was given in the Department of Physics at ANU in 1989 and has since expanded into two full third-year/masters lectures courses, one of which covers all the fundamentals of the physics of guided wave photonics with a focus on application to longdistance optical transmission systems covering fibres and waveguides and associated lightprocessing devices. The second more recent course established in 2007 addresses the application of guided wave photonics to non-telecommunications areas including sensing, security, architecture, transport, biophotonics including endoscopy and dosimetry, astronomy and the emerging area of nanophotonics.

The lecture material in these courses has evolved with sufficient detail to minimise reliance on existing photonics texts that are either very expensive, too advanced or provide insufficient physical background and explanation. 
Both courses have a well-developed laboratory component comprising around 6-7 experiments that are continually upgraded. The first course experiments embrace: (i) multimode fibre propagation characteristics; (ii) single-mode fibre and bend loss; (iii) constructing and testing a singe-mode fibre communication link; (iv) optical time domain reflectometry (OTDR); (v) fibre couplers, connectors and wavelength division multiplexing (WDM); (vi) erbium-doped fibre amplifiers, and (vii) pulse dispersion in single mode fibres. Experiments (i) to (v) are hands-on while experiments (vi) and (vii) are PC-based using Australia-developed software from VPI. For the second course, the laboratory experiments include: (i) optical fibre refractometry; (ii) Fabry-Perot sensor; (iii) fibre gyroscope; (iv) optical fibre lighting and energy use; (v) fibre Bragg grating sensor; and (vi) optical time domain relfectometry (OTDR) sensing.

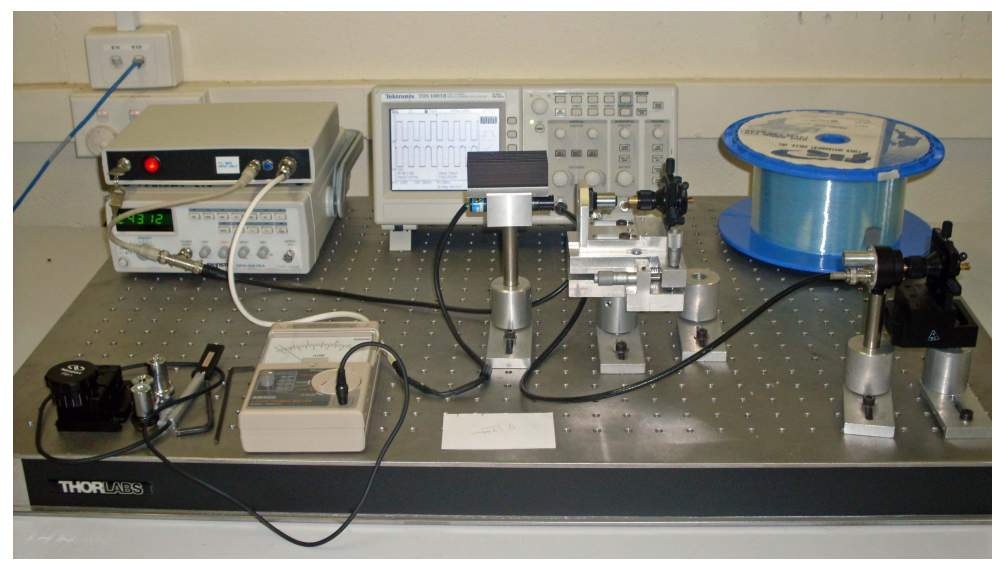

Digital optical communications laboratory experiment

In addition to these traditional lecture/laboratory courses, a half-course was introduced some years ago that is devoted to photonics work experience and places students with local photonics companies in Canberra for at least 30 hours of hands-on practical experience. There is no formal examination involved but the course requires a detailed work log and an essay covering the background to the area of photonics undertaken. Encouragingly, several students who have taken this course have gone on to work with the company involved on either a part-time or full-time basis.

All of the above courses are available to both engineering and physics students, with the majority of engineering students comprising Master of Engineering students from overseas. Masters students are expected to complete an essay assignment and give a presentation in the two major courses instead of further assignments. Guided wave photonics has also appeared to a lesser extent in other physics courses including first- and third-year courses, and guest lectures have been given in some other undergraduate engineering courses.

ANU was also instrumental is helping to establish photonics courses at other Australian universities and institutions. The bulk of an inaugural photonics lecture course was delivered by ANU personnel over a 2-month in the School of Electronic and Computer Science at Curtin University in Perth, WA, during 1997. Similarly ANU personnel together with Sydney University people delivered a theoretical and experimental component of a masters degree at the Australian Telecommunications Research Institute (ATRI), also at Curtin University. Closer to home, ANU played a leading role in the establishment of an Advanced Diploma in Photonics Technology at the Canberra Institute of Technology in 2003. 


\section{Undergraduate Photonics Degrees}

The exponential increase in photonics activity in Australia in the 1990's lead to the establishment of special degrees at a number of Australian universities and TAFE's to take advantage of demand. MacQuarie University in Sydney was probably the first entrant into this field and set up an undergraduate degree B.Optoelectronics that involved the local TAFE for the the optical transmission systems training part of the degree. ANU's response was to establish three new photonics degrees, two in physics and one in engineering. The engineering degree was labelled as

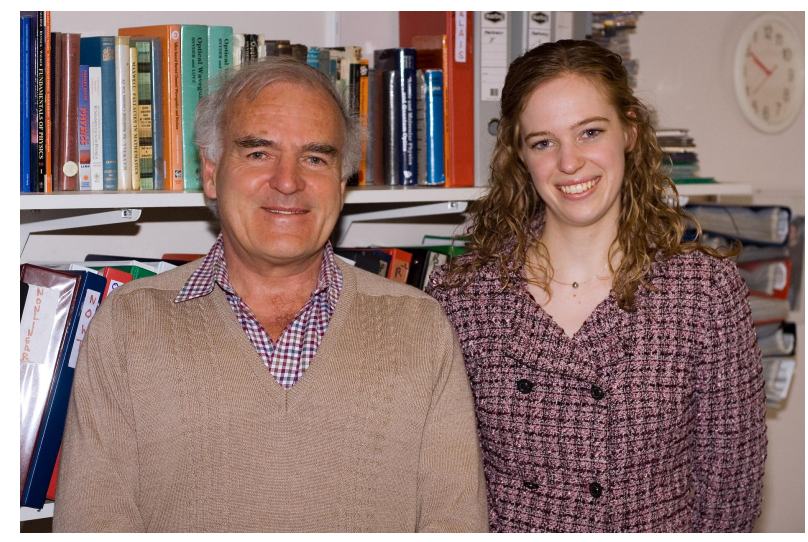

John Love, Convenor of ANU Photonics teaching, with Tegan Donald, recipient of the first B.Photonics degree from ANU in 2006

a B.Photonics Systems but was not successful and was withdrawn a few years later. A B.Photonics degree was introduced by the (then) Department of Physics and has only been recently withdrawn as it attracted nothing like the expected number of students.

\section{Masters Degrees by Coursework}

The one remaining conventional photonics degree at ANU degree is the Master of Photonics (M.Photonics), a 1-year degree also introduced by the (then) Department of Physics. This has been in existence for about 10 years, and although it attracts a healthy number of applicants, only 1 or 2 take the degree each year, the reminder probably deterred by the relatively high level of ANU fees compared to their own country. The degree requirements are currently being revised to reflect available and evolving courses at ANU and the increasing interest in, e.g. photovoltaics integrated into guided wave photonics to increase efficiencies and reduce manufacturing costs. Apart from 6 lecture courses, there will be a research project in photonics undertaken with a group in the Research School of Physics and Engineering and, for the remaining course will be chosen by the student in consultation with the degree convenor.

There is also a photonics component to a distance-learning Master of Contemporary Science (M.Contemp.Sc) degree. This degree was developed to enable schoolteachers, in particular, to come up to speed with recent developments in various areas of science. The current photonics unit is derived from the first photonics course in fibre optics described above, and plans are afoot to add a second unit based on the second course. In addition, students can undertake a supervised research component for which it is necessary to spend siginficant time at ANU in the case of laboratory-based projects. 


\section{Photonics Prizes}

An incentive for students to take the ANU photonics courses was the introduction of the Wanda Henry Prize in 1998. Dr Wanda Henry was the first women to receive a PhD in guided wave photonics at ANU and went on to postdoctoral work at the University of Arizona at Tucson and at Kings College, Cambridge University, where she was a college fellow.

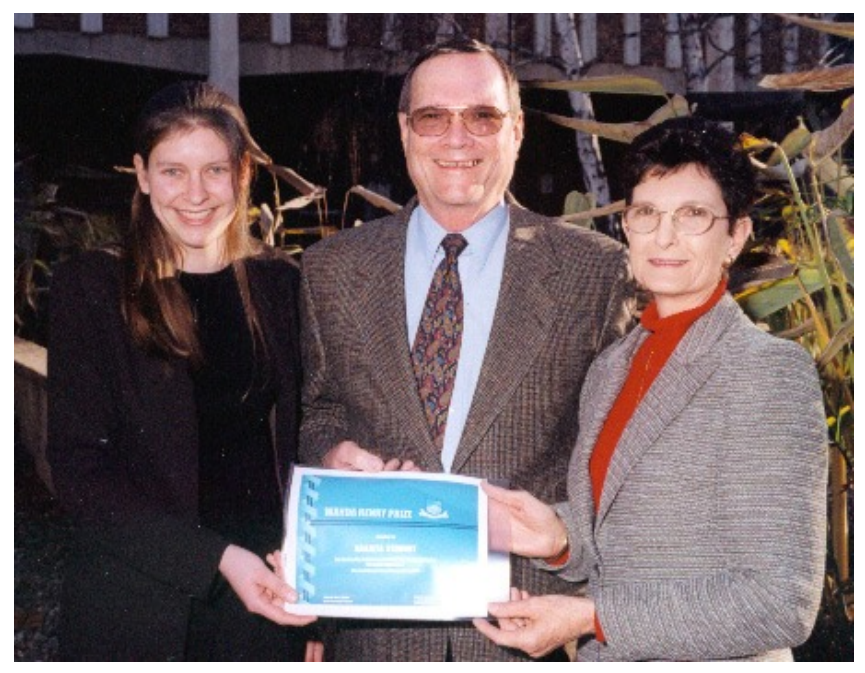

Kallista Stewart (left) receives the inaugural Wanda Henry Prize from parents Bob and Margaret Henry in 1998

She took up a permanent position in the Department of Electronic Engineering at La Trobe University in Melbourne in 1994 but sadly passed away in 1996 at the age of 35. In view of her great enthusiasm and strong support for photonics throughout her brief career, a number of prizes were established in her memory. One of these is at Aldridge State High School in Queensland, at the annual Australian Conference on Optical Fibre Technology (ACOFT) and at ANU, in addition to a Bursary at La Trobe University

\section{Photonics Teaching Kits}

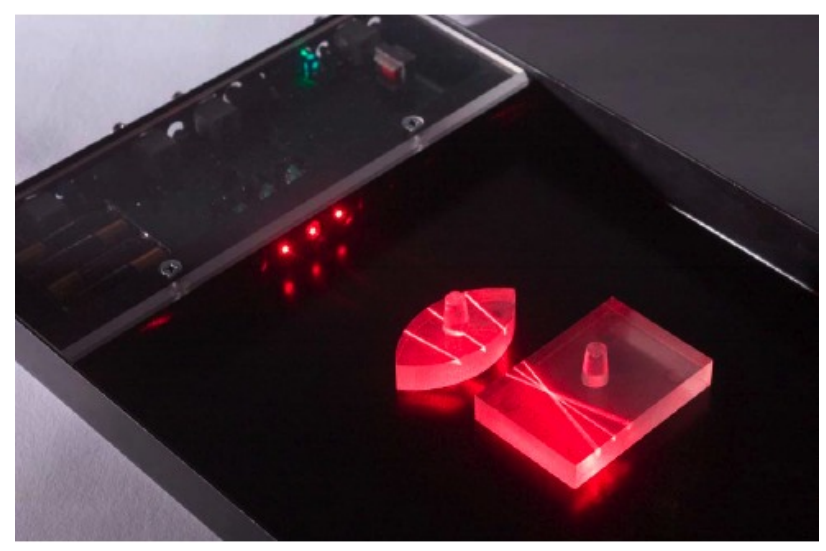

Minilab /I showing the laser outputs for ray tracing experiments 
The Department of Quantum Science also manufactures and markets the Minilab that is a comprehensive kit-in-a-box that enables a wide range of basic experiments to be undertaken in optics, photonics, quantum optics and electronics. The photonics component covers optical fibre basics, such as light launching and excitation, bound rays, attenuation and dispersion using ray tracing, as well as digital modulation, splicing, wavelength multiplexing and simple fibre sensors.

At present a more compact, simpler and more portable purely photonics kit is being developed and tested in the field for use in years 10-12 school laboratories by Sandy Box, a retired ACT science teacher with many years experience, as part of the research component of her Master of Contemporary Science degree at ANU.

\section{Outreach}

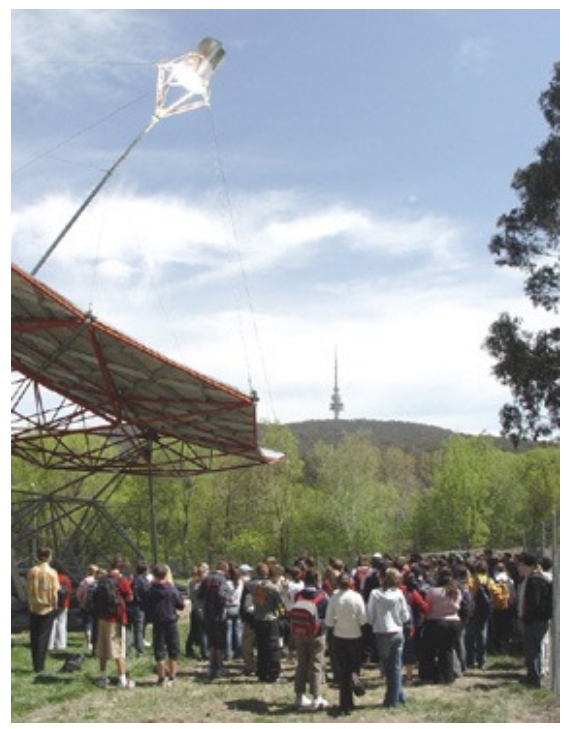

Siemens Science Experience students at the ANU solar dish

Photonics outreach has matched the peaks and troughs in the photonics industry in Australia but now seems to have settled down to a moderate but steadily increasing level of activity. In the

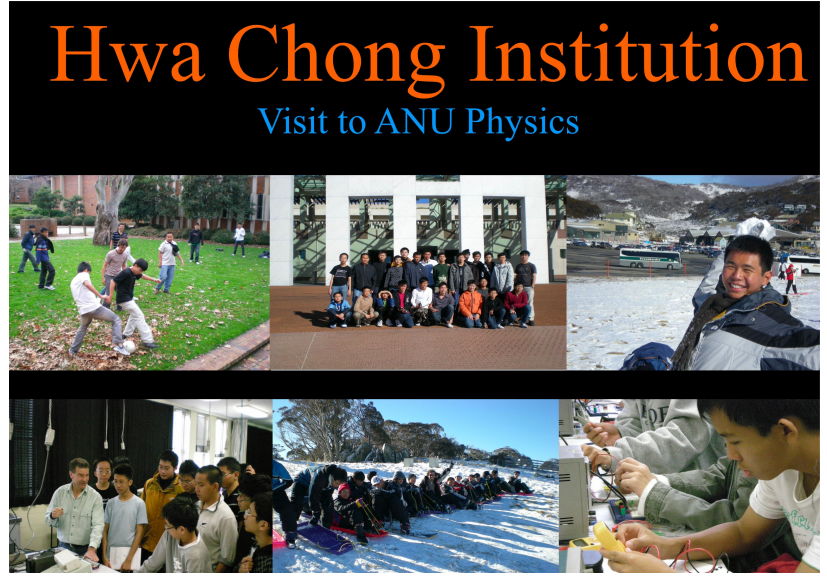

Montage of Singapore school visit to ANU 
1990's and early 2000's, a number of companies were eager to be appraised of the new technology and a variety of brief introductory professional courses were tailor-made to order by ANU researchers and teachers. ANU photonics is also promoted through the annual National Science Festival held in Canberra and individuals make give occasional presentations to local schools and other organisations.

From 1991 to 2004, photonics in both lecture and hands-on form was also presented as part of the annual ANU-managed Siemens Science and Engineering Experience in the ACT for year 9 students. The Experience was designed to help these students make better-informed decisions about science and engineering courses for years 11 and 12 at college and on to university. Overseas groups regularly visit from Singapore for intensive few-day Science Schools with age groups as young as year 8 .

\section{Australian Photonics Cooperative Research Centre}

The Australian Photonics Cooperative Research Centre was established in 1992 based on major Commonwealth Government funding and ran for 13 years until funding was exhausted. The Centre consisted of an amalgamation of collaborating universities, including ANU, and commercial partners to foster the development, application and commercialisation of photonics research. In addition to the strong research focus, the Centre also fostered a range of photonics teaching and training initiatives. On of the early ideas was the establishment of a number of scholarships exclusively for suitably qualified women postgraduate research students.

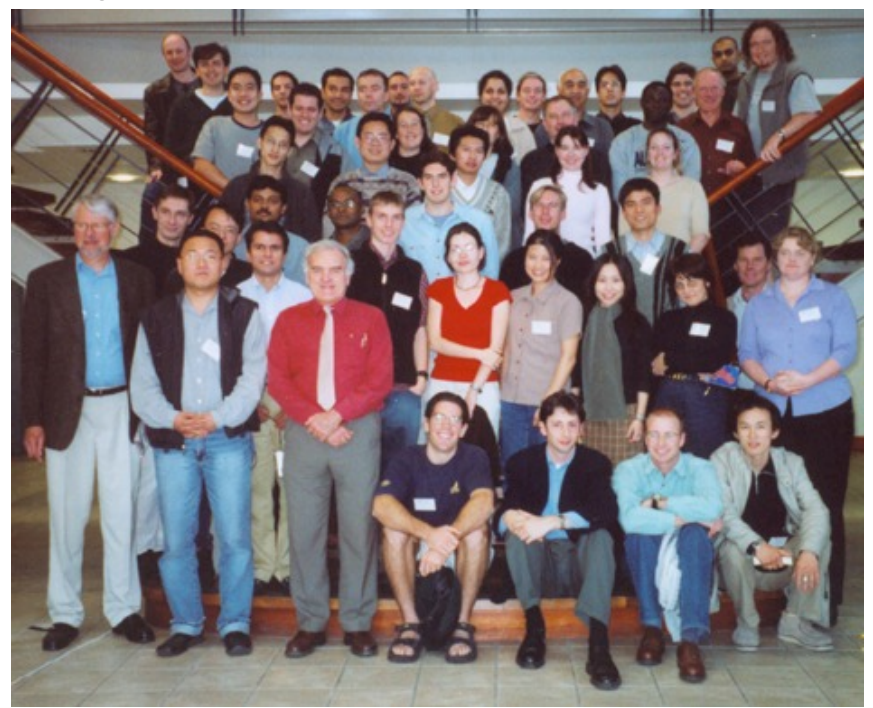

Delegates and presenters at the 2001 Australian Photonics School in Sydney

Another development was the introduction of Photonics Schools held over a few-day period prior to the annual Australian Conference on Optical Fibre Technology. The purpose of these Schools was primarily to broaden the photonics knowledge of research students beyond their only more narrowly focused doctoral research projects. In the event these Schools attracted other participants from government and industry, including the legal profession, the latter probably a reflection on the large number of patents being generated. Each School ran over a period of 2-3 days and comprised guest and regular lectures on different aspects of photonics, including contracts and patents. A halfday hands-on session was a popular component of the Schools. 
Later Photonics Schools based on the above model and supported with Australian Commonwealth Government and local funding were run successfully in collaboration with tertiary institutions in Sweden, Singapore, Korea and China.

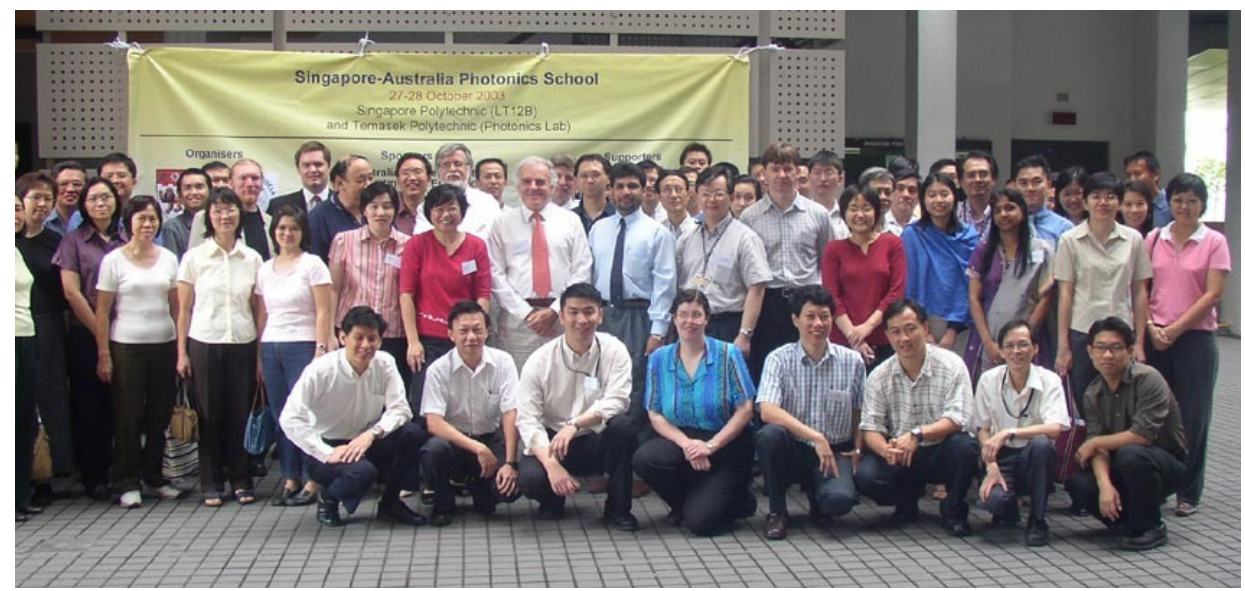

Delegates at the Singapore-Australia Photonics School in 2004

Later in the CRC's history, a company - the Photonics Institute - was set up at the Canberra Institute of Technology to help integrate and plan the increasing level of photonics education and training activities. Part of the Institute's remit was the development of a number of photonics modules that could be used by CRC-associated and other institutions for their internal teaching purposes. It also became involved in supporting the introduction of photonics into school curricula in a number of states, as well as into national training schemes. Most regrettably, the achievement of many of these goals was frustrated by the unplanned cessation of virtually all the CRC's activities in 2005 caused by financial problems.

\section{Future Developments}

It is a challenge to try and predict with reasonable certainty how photonics education and training at ANU will evolve over the next few years. The basic teaching courses outlined above have a sufficiently strong base and demand to ensure their continued presentation for the foreseeable future. However, ANU has moved to a collegiate structure that has resulted in closer integration between the traditional undergraduate photonics teaching areas in the former Faculties and the graduate photonics teaching areas in the Research Schools. This amalgamation should in principal lead to enhanced involvement of researchers in photonics teaching, but current organisational and financial constraints may frustrate its rapid achievement.

\section{Acknowledgements}

I am grateful to Andrew Papworth who oversees the photonics teaching laboratories at ANU for providing material for this paper and to Dr Kate Wilson for financial support to help attend ETOP. Dr Anna Wilson, President of the ACT Branch of the Australian Institute of Physics (AIP), secured financial support from the AIP to help with the development of the new photonics kit for use in Canberra high schools. 